University of Nebraska - Lincoln

DigitalCommons@University of Nebraska - Lincoln

2000

\title{
A Surface-Associated Activity Trap for Capturing Water-Surface and Aquatic Invertebrates in Wetlands
}

\author{
Mark A. Hanson \\ Minnesota Department of Natural Resources \\ Christiane C. Roy \\ Kansas Department of Wildlife and Parks \\ Ned H. Euliss Jr. \\ U.S. Geological Survey, ceuliss@usgs.gov \\ Kyle D. Zimmer \\ North Dakota State University - Main Campus \\ Michael R. Riggs \\ Research Triangle Institute \\ See next page for additional authors
}

Follow this and additional works at: https://digitalcommons.unl.edu/usgsnpwrc

Hanson, Mark A.; Roy, Christiane C.; Euliss, Ned H. Jr.; Zimmer, Kyle D.; Riggs, Michael R.; and Butler, Malcolm G., "A Surface-Associated Activity Trap for Capturing Water-Surface and Aquatic Invertebrates in Wetlands" (2000). USGS Northern Prairie Wildlife Research Center. 265.

https://digitalcommons.unl.edu/usgsnpwrc/265

This Article is brought to you for free and open access by the US Geological Survey at DigitalCommons@University of Nebraska - Lincoln. It has been accepted for inclusion in USGS Northern Prairie Wildlife Research Center by an authorized administrator of DigitalCommons@University of Nebraska - Lincoln. 


\section{Authors}

Mark A. Hanson, Christiane C. Roy, Ned H. Euliss Jr., Kyle D. Zimmer, Michael R. Riggs, and Malcolm G. Butler 


\title{
NOTE
}

\section{A SURFACE-ASSOCIATED ACTIVITY TRAP FOR CAPTURING WATER-SURFACE AND AQUATIC INVERTEBRATES IN WETLANDS}

\author{
Mark A. Hanson ${ }^{1}$, Christiane C. Roy ${ }^{2,5}$, Ned H. Euliss, Jr. ${ }^{3}$, Kyle D. Zimmer ${ }^{2}$, Michael R. Riggs ${ }^{4,6}$, \\ and Malcolm G. Butler ${ }^{2}$ \\ ${ }^{1}$ Minnesota Department of Natural Resources \\ Wetland Wildlife Populations and Research Group \\ $10223^{\text {rd }}$ St. NE \\ Bemidji, Minnesota, USA 56601 \\ ${ }^{2}$ Department of Zoology \\ North Dakota State University \\ Fargo, North Dakota, USA 58105 \\ ${ }^{3}$ U.S. Geological Survey \\ Biological Resources Division \\ Northern Prairie Wildlife Research Center \\ $871137^{\text {th }}$ St. SE \\ Jamestown, North Dakota, USA 58401-7317 \\ ${ }^{4}$ Minnesota Department of Natural Resources \\ Carlos Avery Wildlife Management Area \\ 18310 Zodiac \\ Forest Lake, Minnesota, USA 55025 \\ ${ }^{5}$ Present address: \\ Kansas Department of Wildlife and Parks \\ P.O. Box 1525 \\ Emporia, Kansas, USA 66801 \\ ${ }^{6}$ Present address: \\ Statistics Research Division \\ Research Triangle Institute \\ P.O. Box 12194 \\ Research Triangle Park \\ North Carolina, USA 27709-2194
}

\begin{abstract}
We developed a surface-associated activity trap (SAT) for sampling aquatic invertebrates in wetlands. We compared performance of this trap with that of a conventional activity trap (AT) based on nondetection rates and relative abundance estimates for 13 taxa of common wetland invertebrates and for taxon richness using data from experiments in constructed wetlands. Taxon-specific non-detection rates for ATs generally exceeded those of SATs, and largest improvements using SATs were for Chironomidae and Gastropoda. SATs were efficient at capturing cladocera, Chironomidae, Gastropoda, total Crustacea, and multiple taxa (taxon richness) but were only slightly better than ATs at capturing Dytiscidae. Temporal differences in capture rates were observed only for cladocera, Chironomidae, Dytiscidae, and total Crustacea, with capture efficiencies of SATs usually decreasing from mid-June through mid-July for these taxa. We believe that SATs may be useful for characterizing wetland invertebrate communities and for developing improved measures of prey available to foraging waterfowl and other aquatic birds.
\end{abstract}

Key Words: Activity traps, aquatic invertebrates, experimental wetlands, sampling 


\section{INTRODUCTION}

Waterfowl biologists were among the first to recognize the functional importance of aquatic invertebrates in freshwater wetlands (reviewed by Krapu and Reinecke 1992). Wetland invertebrates are vital links between products of primary production and various guilds of vertebrate consumers (Murkin and Wrubleski 1988). Invertebrates also influence organic matter decomposition rates, translocation and cycling of nutrients (Murkin and Wrubleski 1988), and other biotic and abiotic characteristics of wetland environments, such as phytoplankton biomass and water transparency (Bouffard and Hanson 1997). Invertebrate community structure has been used widely to assess ecological characteristics of lotic habitats (Resh and Jackson 1993), and such an approach recently has been proposed for prairie wetlands (Adamus 1996).

Studies of aquatic invertebrates in wetlands are severely bounded by limitations of available sampling gear and techniques. Invertebrate sampling in prairie wetlands is difficult because these systems are structurally complex and invertebrate populations are dynamic and patchily distributed. Researchers have developed a variety of traps for collecting invertebrates, yet all these sampling devices impart biases, which are rarely assessed.

Conventional activity traps (ATs), usually modified after designs of Whitman (1974), Swanson (1978), Murkin et al. (1983), or Ross and Murkin (1989), are widely used for semiquantitative invertebrate sampling in prairie wetlands (Murkin et al. 1983, Ross and Murkin 1989, Bataille and Baldassare 1993, Hanson and Riggs 1995, and many others). ATs are light, portable, and inexpensive to construct. ATs may be deployed horizontally or vertically and at various depths, depending on wetland characteristics and specific study objectives. More importantly, ATs perform well in terms of number and diversity of invertebrates captured, and sample processing time is usually shorter than that associated with more quantitative gear (such as sweep nets, Gerking, or sediment core samplers) (Murkin et al. 1983, Brinkman and Duffy 1996, Turner and Trexler 1997). Additionally, they gather clean samples containing little organic material, sediment, plant fragments, etc. Clean samples result in shorter sample processing times and often allow more intensive sampling, thus reducing magnitude of within-wetlands variance estimates.

We used ATs similar to those described by Swanson (1978), Murkin et al. (1983), and Ross and Murkin (1989) in studies assessing influences of invertebrate availability on early growth and survival of young mallard ducklings (Cox et al. 1998). We also developed surface-associated ATs (SATs) to better sample invertebrates in the primary duckling feeding zone. We defined this region as a vertical stratum $25.40 \mathrm{~cm}$ thick, extending from $15.24 \mathrm{~cm}$ below to $10.16 \mathrm{~cm}$ above the water surface. We assessed performance of our SATs in relation to ATs by comparing non-detection rates and relative abundance estimates of capture for 13 taxa of common aquatic invertebrates. We discuss implications of these results for future investigators, especially researchers interested in sampling invertebrates available to foraging birds such as young ducklings.

\section{STUDY SITE}

We conducted our study during 1993-95 at Northern Prairie Wildlife Research Center (NPWRC), Jamestown, North Dakota, USA $\left(46^{\circ} 53^{\prime} \mathrm{N}, 98^{\circ} 38^{\prime} \mathrm{W}\right)$ using a series of 20 constructed earthen wetlands arranged in a $4 \times 5$ grid. Each wetland cell contained 0.04 ha of vegetated upland and a single 0.05 ha wetland with a maximum depth of $1.2 \mathrm{~m}$. Surface area of each wetland was approximately $22 \times 22 \mathrm{~m}$. Basins were contoured to provide a 4:1 slope with a $12 \times 12$ $\mathrm{m}$ center area of maximum depth $(1.2 \mathrm{~m})$. During our three-year study, we managed all wetlands to simulate a semi-permanent hydroperiod (Stewart and Kantrud 1971). Wetlands were flooded with well water to maximum depth during 25 April-5 May and were drawn down to depths of approximately $40 \mathrm{~cm}$ each year by 1 September. Wetland characteristics and management regimes are discussed in more detail in Hanson et al. (1995) and Cox et al. (1998).

\section{METHODS}

\section{Trap Design}

SATs and ATs were of similar size (Figure 1a,b) within constraints imposed by shape differences between the two trap types. Funnel aperture sizes for ATs were 176.72 and $6.61 \mathrm{~cm}^{2}$ (outside and inside, respectively) compared to $387.10\left(154.84 \mathrm{~cm}^{2}\right.$ above, 232.26 $\mathrm{cm}^{2}$ below the water surface) and $32.26 \mathrm{~cm}^{2}(12.90$ $\mathrm{cm}^{2}$ above, $19.36 \mathrm{~cm}^{2}$ below the water surface) for SATs. Smaller inner funnel openings of ATs may have restricted entrance of some invertebrates, thus influencing trap performance. However, constructing both trap types with funnel openings of identical area was impractical because resulting inside openings of SATs would have been so narrow as to exclude many macroinvertebrates. We constructed SATs from $0.48-\mathrm{cm}-$ thick transparent plexiglass. All pieces were professionally laser-cut to specified dimensions. Traps were assembled at NPWRC using methylene chloride. Assembly time was approximately 15 minutes per trap. 
(a)
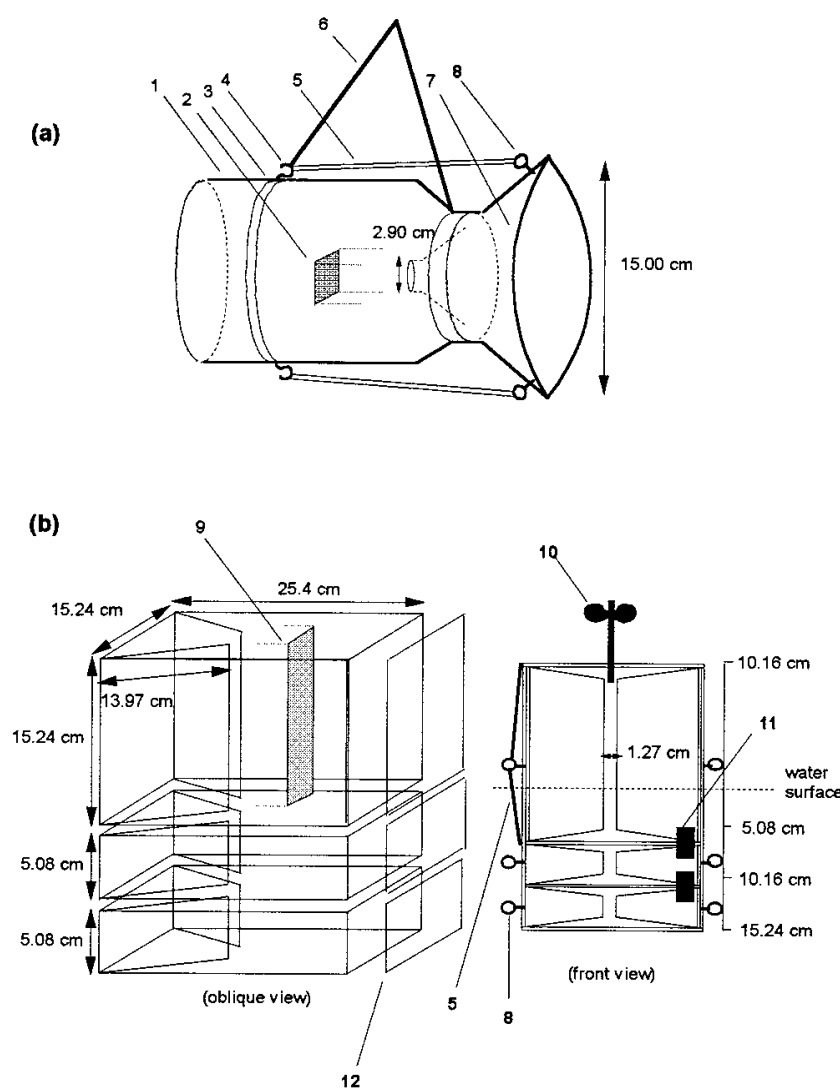

Figure 1. Design of (a) conventional activity trap (AT) and (b) surface activity trap (SAT) for collecting aquatic invertebrates (drawings are not to scale): 1. 1-L glass jar; 2, 9. hardware cloth fish screen; 3 . hose clamp; 4. clip; 5. rubber band; 6. hanger wire; 7. transparent powder funnel, polymethylpentene; 8 . eye screw; 10. wing nut; 11 . binder clip; and 12 . removable PVC back.

We adjoined SAT strata using small office binder clips to allow disassembly during sample collection; alternatively, strata could be permanently joined using methylene chloride. We fitted the rear portion of each SAT stratum with a removable insert so trap contents could be removed easily (Figure $1 b$ ); inserts were held in place with rubber bands but could be installed permanently. Cost of material for each SAT was approximately \$15 (U.S.); this contrasts with about \$5 (U.S.) for each AT constructed after the general design of Ross and Murkin (1989).

To satisfy objectives of a concurrent study, fathead minnows (Pimephales promelas [Rafinseque]) were added to 10 randomly chosen study wetlands each year (10 wetlands remained fishless). To exclude fish and limit depredation of invertebrates within ATs and SATs (Murkin et al. 1983, Elmberg et al. 1992), we placed 1.4-cm-diameter wire mesh over inside openings of all funnels (ATs and SATs), leaving a 1-cm gap between inside funnel openings and mesh (Figure 1). Most in-

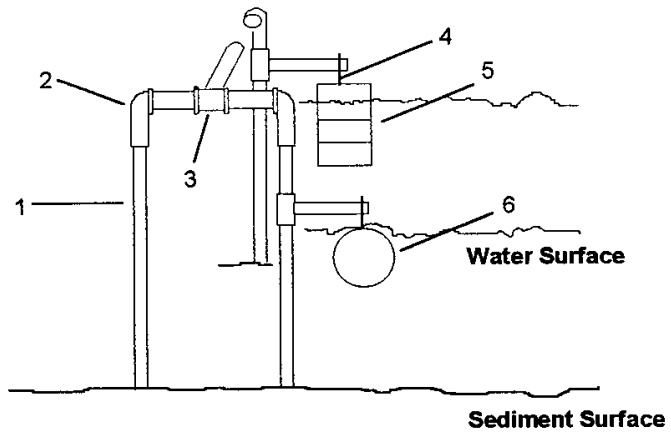

Figure 2. General orientation used in deploying surface activity traps (SAT) and conventional activity traps (AT) in study wetlands: 1 . 0.3-cm-ID PVC pipe; 2. PVC elbow; 3. PVC Tee; 4. bolt with wing nut; 5. SAT; and 6. AT.

vertebrate taxa were still capable of entering traps (including adult Dytiscidae, Zygoptera, and Lethocerus [Belostomatidae]); fish were captured only rarely.

\section{Sampling Protocol and Trap Deployment}

Invertebrates were sampled 3 times (periods 1-3) each year between 10 June and 15 July using horizontally-positioned ATs and SATs (Figure 1a,b). Both trap types were deployed concurrently for 24-hr exposure periods. In contrast to conventional ATs, SATs were comprised of three compartments and thus were designed to sample discrete vertical zones from $10.16 \mathrm{~cm}$ above to $15.24 \mathrm{~cm}$ below the water surface (Figure 1b). All trap contents were condensed by passing samples through a $0.4 \mathrm{~mm}$ funnel and preserved with $70 \%$ ethanol. In the lab, invertebrates were identified to the lowest feasible taxonomic group using Merritt and Cummins (1984) and Pennak (1989). Taxonomic resolution varied, but identification was usually made to family or genus.

Matched pairs of traps were deployed horizontally from PVC frames fastened in sediments along a single randomly chosen linear transect in each wetland. Each PVC frame held one SAT and one AT approximately $0.3 \mathrm{~m}$ beneath the water surface (Figure 2). Four PVC frames, hence 4 paired AT and SAT combinations (trap pairs) were deployed simultaneously in each wetland for $24 \mathrm{hrs}$. One frame (thus one trap pair) was deployed at each of 4 depth locations $(0.3,0.6,0.9$, and $1.2 \mathrm{~m}$ ) in each wetland. Based on funnel dimensions, ATs sampled the upper $15 \mathrm{~cm}$ of the wetland water column; likewise, SATs sampled approximately the upper $15 \mathrm{~cm}$ of the water column as well as the water surface and region $10.16 \mathrm{~cm}$ above. This design yielded 720 samples from independent matched pairs of traps over the 3 years of our study. 


\section{Statistical Analyses}

Non-detection Rates. We assessed abilities of SATs and ATs to detect presence of each of 13 invertebrate taxa. Each trap was scored 1/0 for each taxon based on presence/absence of at least 1 individual. Our question of interest was whether non-detection probabilities (for each taxon) were greater for ATs than for SATs in each matched pair. We tested this hypothesis using McNemar's test (Agresti 1996:227-228) separately by sampling period and fish presence/absence. First, we calculated the proportion (with $95 \%$ confidence limits) of SATs that did not detect any organisms, then the additional proportion (with $95 \%$ confidence limits) of ATs that failed to detect any organisms. The latter was always positive and represents the extent to which SATs improve on ATs (i.e., the estimated sampling device effect). Essentially, McNemar's test evaluates whether these device effects differed significantly from zero (Agresti 1996:227-228). To assess seasonal and/ or fish-related differences in strength of device effects, a dichotomous score was created for each trap pair such that a pair received a score of 1 if the SAT detected a taxon, but the AT did not. Pairs were assigned a score of 0 for all other outcomes. For each taxon, we modeled the 0,1 score as a linear function of the fixed effects of the fish treatment and period; wetlandswithin-years was treated as a random effect. We used the SAS GLIMMIX macro (after Littell et al. 1996) to fit this generalized linear mixed model (Breslow and Clayton 1993) with a binomial error structure.

Relative Abundance of Invertebrates. We assessed paired differences in numbers of organisms (each of 13 selected taxa and taxon richness) captured by ATs and SATs, conditional on at least 1 pair member trapping $\geq 1$ organism from each taxon. We excluded from our analysis trap pairs wherein individual taxa were not detected by either device because these pairs contributed no information on differential trapping ability. We based our analysis for taxon richness on all taxa captured, not just the 13 selected groups used in assessing non-detection and relative abundance.

We analyzed paired differences in log-relative abundance of each taxon, plus taxon richness of the trap contents. Log transformations were required because our relative abundance data were severely skewed. We fit a linear model to the paired log-differences, modeling year and pond as random block effects and sampling period and fish presence/absence as fixed effects. As in our non-detection rate analysis, we obtained estimates of paired differences for each of the 6 sample period/fish fixed effects combinations and tested the null-hypothesis that each difference was zero. Differences were back-transformed and reported along with 95\% confidence intervals. The back-transformed value of a log-difference has special utility for assessing effects associated with a new treatment (e.g., SAT) relative to a more traditional one (e.g., AT) (Keene 1995). Algebraically our improvement ratios were

$$
\operatorname{Exp}[\log (\mathrm{SAT})-\log (\mathrm{AT})]=\mathrm{SAT} / \mathrm{AT}
$$

where: $\mathrm{SAT} / \mathrm{AT}=$ ratio of the estimated geometric treatment means.

This improvement ratio measures multiplicative improvement in the capture efficiency associated with using an SAT instead of an AT. Ratios whose $95 \%$ confidence limits include 1.0 imply no improvement, whereas ratios with lower bounds on their $95 \%$ confidence limits $>1.0$ imply significant improvement in capture efficiency due to use of SATs. We used SAS PROC MIXED (Littell et al. 1996) to fit the model and to obtain (1) adjusted catch-ratio estimates, (2) paired t-tests, and (3) F-tests for improvement-ratio differences resulting from sampling period and/or presence of fathead minnows.

Vertical Position Within SATs. SATs were initially developed to facilitate comparisons among catches of organisms associated with discrete water-column strata. We assessed potential differences (top, middle, bottom strata of each SAT) in non-detection probabilities and paired differences in log-relative abundance of each of our 13 invertebrate taxa using McNemar's test (Agresti 1996:227-228) and SAS PROC MIXED (Littell et al. 1996) as described above. Again, we modeled year and pond as random block effects and sampling period, fish presence/absence, and vertical position (top, middle, bottom) as fixed effects.

\section{RESULTS}

\section{Non-detection Rates}

Non-detection rates of SATs varied markedly among taxa, ranging from $0 \%$ for total insects (all taxa combined) to $86.0 \%$ for Ephemeroptera during sampling period 2 (Table 1). Non-detection rates (AT-SAT) were always positive and $>0$, indicating that detection by SATs was always greater than that of matched ATs, regardless of taxon. We observed largest detection differences with Gastropoda and Chironomidae. Whenever our generalized mixed-models tests indicated significant differences among sampling periods or wetland type, we tabulated separate estimates for each level of the significant effect. Otherwise, we computed a pooled estimate over all levels of the effect variable (Table 1). Our mixed model results indicated that nondetection rates (AT-SAT) for Ephemeroptera approximately doubled by our third sampling period $(\mathrm{P}=$ 0.0014). No other temporal interactions with device effects were evident (Table 1). Non-detection rates 
Table 1. Comparison of conventional (AT) vs. surface-associated (SAT) activity trap non-detection rates (\%) for 13 invertebrate taxa by wetland type and sampling period. AT-SAT differences in non-detection rates indicate the percentage of times ATs failed to detect invertebrates that were detected by paired SATs. Data are pooled across sampling period and wetland type except when our models indicated that these interacted with non-detection rates. McNemar's tests evaluate $\mathrm{H}_{0}$ : AT-SAT paired rate difference $=0 \%$.

\begin{tabular}{|c|c|c|c|c|c|c|c|}
\hline Taxon & $\begin{array}{l}\text { Sampling } \\
\text { Period }\end{array}$ & $\begin{array}{l}\text { Wetland } \\
\text { Type }\end{array}$ & $\begin{array}{c}\text { Total } \\
\text { Matched } \\
\text { Pairs }\end{array}$ & $\begin{array}{l}\text { Non-detection } \\
\text { Rate of SATs }\end{array}$ & $\begin{array}{c}\text { AT-SAT } \\
\text { Non-detection } \\
\text { Rate }\end{array}$ & $\begin{array}{l}\text { McNemar's } \\
\text { Chi sq. }\end{array}$ & P-Value \\
\hline & All & No Fish & 355 & $3.7(1.7,5.6)$ & $9.9(6.5,13.2)$ & 29.88 & $<0.00001$ \\
\hline Chironomidae & All & All & 713 & $14.0(11.5,16.6)$ & $43.2(39.3,47.1)$ & 282.33 & $<0.00001$ \\
\hline Corixidae & All & All & 713 & $17.8(15.0,20.6)$ & $20.2(16.4,24.0)$ & 93.41 & $<0.00001$ \\
\hline Dytiscidae & All & All & 713 & $42.8(39.1,46.4)$ & $5.3(1.2,9.5)$ & 6.28 & 0.01222 \\
\hline \multirow[t]{3}{*}{ Ephemeroptera } & 1 & All & 240 & $75.8(70.4,81.2)$ & $11.3(5.6,16.9)$ & 14.29 & 0.00016 \\
\hline & 2 & All & 235 & $86.0(81.5,90.4)$ & $10.6(5.9,15.4)$ & 17.86 & 0.00002 \\
\hline & 3 & All & 238 & $66.0(59.9,72.0)$ & $20.6(14.9,26.2)$ & 42.12 & $<0.00001$ \\
\hline Gastropods & All & All & 713 & $12.3(9.9,14.8)$ & $37.2(33.5,40.8)$ & 257.23 & $<0.00001$ \\
\hline Odonata & All & All & 713 & $65.8(62.3,69.3)$ & $22.0(18.5,25.6)$ & 121.42 & $<0.00001$ \\
\hline Total Insects & All & All & 713 & $0.1(0.0,0.4)$ & $8.4(6.3,10.5)$ & 58.06 & $<0.00001$ \\
\hline Total Crustacea & All & All & 713 & $3.6(2.3,5.0)$ & $14.2(11.4,16.9)$ & 90.27 & $<0.00001$ \\
\hline
\end{tabular}

(AT-SAT) were greater for cladocera $(\mathrm{P}=0.0001)$ in wetlands with fathead minnows but higher for Culicidae $(P=0.0031)$ and Notonectidae $(P=0.0017)$ in fishless sites (Table 1).

\section{Invertebrate Relative Abundance}

SATs also offered considerable improvement over conventional ATs in terms of relative numbers of invertebrates captured. Magnitudes of median-paired SAT-AT differences (Table 2) reflect both local invertebrate abundance and differential trap efficiency. However, improvement ratios (Table 2; obtained by back-transformation of mixed-model estimates of paired log-differences) demonstrate relative efficiency of our SATs vs. ATs after adjustment for blocking factors and independent of actual local abundance. Nearly all ratios were $>1.0$ (in 2 cases for dytiscids, lower limits of confidence intervals included 1.0), indicating that SATs captured more invertebrates than ATs, at least under our matched conditions. As above, whenever our tests indicated significant differences among sampling periods or wetland type, we tabulated separate estimates for each level of the significant effect. Otherwise, we computed a pooled estimate over all levels of the effect variable (Table 2). SATs were most efficient at capturing cladocera, Chironomidae, Gastropoda, total Crustacea (taxa combined), and multiple taxa (taxon richness). On the other hand, SATs were better than ATs at capturing Dytiscidae only during sampling period 1 (Table 2). Significant temporal differences in improvement ratios were observed only for cladocera $(\mathrm{P}=0.0016)$, Chironomidae $(\mathrm{P}<0.0001)$, Dytiscidae $(\mathrm{P}<0.0001)$, and total Crustacea $(\mathrm{P}<$ $0.0001)$. Improvement ratios of SATs for all these taxa were greater during sampling period 1. Improvement ratios differed consistently in relation to fish presence/ absence only for cladocera, whose ratios were larger in fishless wetlands (Table 2).

\section{Vertical Position within SATs}

Only rarely did we observe non-detection differences among SAT strata, but occasionally Notonectidae, Dytiscidae, and Hydrophilidae were more frequently detected in uppermost strata (upper $10 \mathrm{~cm}$ including water surface; all $\mathrm{P} \leq 0.01$ ). Improvement ratios (based on paired log-relative abundance counts) differed only rarely and only for cladocera; more cladocera were captured in the bottom strata (10.16-15.24 $\mathrm{cm}$ beneath water surface). Given that vertical differences in non-detection rates or log-relative abundance were infrequent, we combined catches from all 3 layers for each SAT, treating their contents as a single measure of trap performance in all analyses. 
Table 2. Relative abundances of 13 invertebrate taxa and taxon richness trapped by surface-associated (SATs) vs. conventional (ATs) activity traps. SAT/AT improvement ratios indicate how many times greater the abundance of organisms trapped by SATs were relative to paired ATs. Data are pooled across sampling period and wetland type except when our models indicated that these interacted with improvement ratios. Paired t-tests evaluate $\mathrm{H}_{0}$ : SAT/AT $=1.0$.

\begin{tabular}{|c|c|c|c|c|c|c|c|}
\hline Taxon & $\begin{array}{l}\text { Sampling } \\
\text { Period }\end{array}$ & $\begin{array}{l}\text { Wetland } \\
\text { Type }\end{array}$ & $\begin{array}{l}\text { No. } \\
\text { Matched } \\
\text { Pairs }\end{array}$ & $\begin{array}{l}\text { Median Diff. } \\
( \pm 95 \% \text { C.L.) }\end{array}$ & $\begin{array}{c}\text { Improvement } \\
\text { Ratio } \\
( \pm 95 \% \text { C.L. })\end{array}$ & $\begin{array}{l}\text { Paired } \\
\text { t-test }\end{array}$ & P-Value \\
\hline & 1 & No Fish & 120 & $112.3(79.0,180.0)$ & $6.9(5.4,8.7)$ & 15.87 & $<0.00001$ \\
\hline & 2 & Fish & 99 & $6.5(4.0,11.5)$ & $3.0(2.3,3.9)$ & 8.39 & $<0.00001$ \\
\hline & 2 & No Fish & 109 & $35.0(21.5,50.5)$ & $3.3(2.6,4.3)$ & 9.56 & $<0.00001$ \\
\hline \multirow[t]{3}{*}{ Chironomidae } & 1 & All & 229 & $8.5(7.0,10.0)$ & $5.0(4.4,5.8)$ & 23.20 & $<0.00001$ \\
\hline & 2 & All & 203 & $4.5(4.0,5.5)$ & $3.5(3.0,4.0)$ & 17.02 & $<0.00001$ \\
\hline & 3 & All & 181 & $2.5(2.0,3.0)$ & $2.6(2.2,3.0)$ & 12.42 & $<0.00001$ \\
\hline Corixidae & All & All & 586 & $3.5(3.0,4.5)$ & $2.2(2.0,2.4)$ & 19.91 & $<0.00001$ \\
\hline Culicidae & All & All & 269 & $2.5(2.0,3.5)$ & $2.7(2.4,3.0)$ & 17.13 & $<0.00001$ \\
\hline Gastropoda & All & All & 625 & $16.0(14.0,18.0)$ & $5.5(4.8,6.3)$ & 25.44 & $<0.00001$ \\
\hline Haliplidae & All & All & 150 & $1.0(1.0,1.0)$ & $2.0(1.8,2.2)$ & 14.26 & $<0.00001$ \\
\hline Hydrophylidae & All & All & 243 & $1.5(1.0,1.5)$ & $2.3(2.1,2.4)$ & 21.50 & $<0.00001$ \\
\hline Notonectidae & All & All & 245 & $2.0(1.5,2.0)$ & $2.6(2.3,2.9)$ & 19.11 & $<0.00001$ \\
\hline Odonata & All & All & 244 & $2.0(2.0,2.5)$ & $2.7(2.4,2.9)$ & 22.67 & $<0.00001$ \\
\hline Taxon Richness & All & All & 719 & $17.0(16.5,17.5)$ & $3.6(3.5,3.7)$ & 67.39 & $<0.00001$ \\
\hline \multirow[t]{3}{*}{ Total Crustacea } & 1 & All & 238 & $108.0(90.0,128.0)$ & $6.5(5.5,7.6)$ & 22.77 & $<0.00001$ \\
\hline & 2 & All & 229 & $42.0(32.5,54.0)$ & $4.0(3.4,4.7)$ & 16.62 & $<0.00001$ \\
\hline & 3 & All & 220 & $88.5(67.5,109.0)$ & $4.5(3.8,5.3)$ & 17.75 & $<0.00001$ \\
\hline Total Insects & All & All & 712 & $12.0(10.5,13.5)$ & $2.8(2.6,3.1)$ & 21.21 & $<0.00001$ \\
\hline
\end{tabular}

\section{DISCUSSION}

Investigators often use conventional ATs for sampling wetland invertebrates because these devices are inexpensive, lightweight, and provide samples that are relatively free of sediment and other debris. ATs appear to gather representative samples (Brinkman and Duffy 1996, Turner and Trexler 1997) but are usually deployed as submerged samplers (Ross and Murkin 1989), thus missing surface-associated taxa. We are aware of no other AT designs (besides ours) capable of gathering simultaneous samples of aquatic and semiaquatic invertebrates associated with the wetland water surface except insect emergence traps. We used matching and effect-size estimation to assess performance of SATs relative to conventional and widely used ATs. Such matched-pair designs are widely used to control confounding environmental factors (Manly 1992, Kelsey et al. 1996). In our case, trap matching controlled for variation among years, wetlands, and locations within wetlands. Thus, observed differences resulted from either the device type or interactions with sampling period or presence/absence of fish. We acknowledge that some performance differences between trap types likely resulted from larger funnel apertures of SATs. We made no effort to precisely match trap size characteristics; rather our purpose was to compare performance of our SATs to widely used ATs.

Interpreting biological significance of effect sizes like ours is important for future studies but requires consideration of minimally significant biological differences (MSBD95) (Muller and Benignus 1992, Gerard et al. 1998). Ideally, any sampler that increases information gain would be favored. Yet, use of our SATs is likely to be more expensive and time-consuming than conventional ATs. Thus, in some situations, small information gains with SATs may be biologically unjustified. We suggest that increased expense and effort required to use SATs may be warranted when relative abundance estimates are likely to be at least double that of ATs; that is, the lower bound on the interval estimates of the improvement ratio must be $\geq 2.0$. Detection errors (i.e., declaring a taxon absent when it is not), on the other hand, are likely to have severe implications; resulting errors may be more serious than 
underestimating relative abundance. Thus, we suggest that investigators consider a more conservative value, perhaps $5 \%$, for differences in non-detection rates. For example, we recommend that for assessing presence/ absence of Dytiscidae and Haliplidae, ATs may serve as well as our more expensive SATs (Table 1; lower limit of confidence intervals $<5.0 \%$ ). For other taxa we considered, we believe that SATs are more useful for determining presence/absence. When comparing relative abundance of Dystiscidae (improvement ratios), ATs apparently perform nearly as well as SATs (Table 2; lower limit of confidence intervals $\leq 2.0$ ). For all other taxa we assessed, relative abundance was best determined using SATs. We emphasize that these recommendations are based on our subjective MSBD95 values. Depending on requirements of specific studies, investigators should apply their own MSBD95 criteria. However, data in Tables 1 and 2 will be useful in deciding which trap to use, no matter what level is specified.

Aquatic invertebrate abundance in wetlands remains difficult to assess, even though interest in these organisms as food for waterfowl has been a key issue guiding development of wetland sampling methods. Due to their small size and high buoyancy, young (age 15 days) ducklings forage mostly on surface-associated invertebrates such as emerging insects and pupae (chironomids, culicids, etc.). Later (age approximately 515 days), duckling diets broaden to include subsurface forms such as various crustaceans, insect larvae, gastropods, and others (Chura 1961, Perret 1962, Bartonek and Hickey 1969, Bartonek and Murdy 1970, Swanson and Sargent 1972, Sugden 1973, Swanson 1977, Danell and Sjöberg 1980, Sjöberg and Danell 1982). We believe that our SAT will be useful for sampling the zone where most ducklings forage and for simultaneously collecting surface-associated, nektonic, and planktonic invertebrates, thus providing improved estimates of invertebrates available to foraging ducklings. Because timing of duckling foraging may be difficult to predict (Ringelman and Flake 1980), opportunity for collecting time-integrated samples using SATs (e.g., over a 24-hr period) may also be advantageous for some study objectives.

Invertebrate distribution and movements in prairie wetlands are not well understood. Corkum (1984) documented seasonal horizontal movements of invertebrates in a semipermanent wetland in central Alberta, Canada, but we are not aware of published reports assessing potential vertical distributions of invertebrates. Our SAT may be useful for assessing distribution and movements of invertebrates in prairie wetlands and other lentic habitats, even though we observed differences in vertical capture rates only occasionally and only for Dytiscidae, Hydrophilidae, and Notonectidae.
Alternatively, we suggest that future investigators consider modifying the SAT such that each trap consists of a single chamber (in contrast to three strata). Resulting traps would be easier to use, less expensive (construction costs similar to ATs), and would yield nearly as much information as traps constructed after our original stratified design. In either case, it is plausible that the surface portion of our SAT may capture insects from uplands or adjacent wetlands; thus, investigators should be mindful of this when interpreting catches from the SAT.

Finally, we expected that differences in trap performance would be less evident in wetlands with fathead minnows since predation by minnows sharply reduces abundance, biomass, and taxon richness of many aquatic invertebrates (Hanson and Riggs 1995, Hanson et al. 1995). Suppression of cladocera in wetlands with high densities of fish probably made it more difficult to detect differences in improvement ratios based on data from our study wetlands (Table 2). Yet, for most ecological studies, SATs would still be advantageous because they are much more likely to detect presence of cladocera even when density of these organisms is relatively low in wetlands with fish (Table 1).

\section{ACKNOWLEDGMENTS}

This research was supported by the Wildlife Research Unit of the Minnesota Department of Natural Resources. We thank R. T. Eberhardt and B. Joselyn for extensive financial and logistical support. J. E. Austin, S. D. Gurtin, M. L. Holt, F. J. Ossman, P. J. Pietz, and M. Slivinski provided valuable assistance in collecting and processing invertebrate samples. R. T. Eberhardt, D. M. Mushet, and Walter G. Duffy provided useful comments on early versions of the manuscript.

\section{LITERATURE CITED}

Adamus, P. R. 1996. Bioindicators for assessing ecological integrity of prairie wetlands. Environmental Protection Agency, National Health and Environmental Effects Research Laboratory, Western Ecology Division, Corvallis, OR, USA. EPA/600/R-96/082. U.S.

Agresti, A. 1996. An Introduction to Categorical Data Analysis. John Wiley and Sons. New York, NY, USA.

Bartonek, J. C. and J. J. Hickey. 1969. Food habits of canvasbacks, redheads, and lesser scaup in Manitoba. Condor 71:280-290.

Bartonek, J. C. and H. W. Murdy. 1970. Summer foods of lesser scaup in subarctic taiga. Journal of the Arctic Institute of North America 23:35-44.

Bataille, K. J. and G. A. Baldassarre. 1993. Distribution and abundance of aquatic macroinvertebrates following drought in three prairie pothole wetlands. Wetlands 13:260-269.

Bouffard, S.H. and M.A. Hanson. 1997. Fish in waterfowl marshes: waterfowl managers' perspective. Wildlife Society Bulletin 25: 146-157.

Breslow, N.R. and D.G. Clayton. 1993. Approximate inference in generalized linear mixed models. Journal of the American Statistical Association 88:9-25. 
Brinkman, M. A. and W. G. Duffy. 1996. Evaluation of four wetland aquatic invertebrate samplers and four sample sorting methods. Journal of Freshwater Ecology 11:193-200.

Chura, J. J. 1961. Food availability and preferences of juvenile mallards. North American Wildlife Conference Transactions 26:121133.

Corkum, L. D. 1984. Movements of marsh-dwelling invertebrates. Freshwater Biology 14:89-94.

Cox, R. R., Jr., M. A. Hanson, C. C. Roy, N. H. Euliss, Jr., D. H. Johnson, and M. G. Butler. 1998. Mallard duckling growth and survival in relation to aquatic invertebrates. Journal of Wildlife Management 62:124-133.

Danell, K. and K. Sjöberg. 1980. Foods of Wigeon, teal, mallard and pintail during the summer in a Northern Swedish Lake. Viltrevy $11: 141-167$.

Elmberg, J., P. Nummi, H. Pöysa, and K. Sjöberg. 1992. Do intruding predators and trap position affect the reliability of catches in activity traps? Hydrobiologia 239:187-193.

Gerard, P. D., D. S. Smith, and G. Weerakkody. 1998. Limits of retrospective power analysis. Journal of Wildlife Management 62: 801-807.

Hanson, M. A., C. R. Roy, and K. D. Zimmer. 1995. Bait fish effects on wetland invertebrate communities and mallard ducklings-preliminary results and conclusions. p. 167-196. In B. Joselyn (ed.) Summaries of Wildlife Research Findings 1995. Minnesota Department of Natural Resources, Section of Wildlife, St. Paul, MN, USA.

Hanson, M. A. and M. R. Riggs. 1995. Potential effects of fish predation on wetland invertebrates: a comparison of wetlands with and without fathead minnows. Wetlands 15:167-175.

Keene, O. N. 1995. The log transformation is special. Statistics in Medicine 14:811-819.

Kelsey, J., W. D. Thompson, and A. S. Evans. 1996. Methods in Observational Epidemiology. Oxford University Press, New York, NY, USA.

Krapu, G. L. and K. J. Reinecke. 1992. Foraging ecology and nutrition. p. 1-29. In B. D. Batt, A. D. Afton, M. G. Anderson, C. D. Ankney, D. H. Johnson, J. A. Kadlec, and G. L. Krapu (eds.) Ecology and Management of Breeding Waterfowl. University of Minnesota Press, Minneapolis, MN, USA.

Littell, R. C., G. A. Milliken, W. W. Stroup, and R. D. Wolfinger 1996. SAS System for Mixed Models. SAS Institute Inc., Cary, NC, USA.

Manly, B. F. 1992. The Design and Analysis of Research Studies. Cambridge University Press, New York, NY, USA.

Merritt, R. W. and K. W. Cummins (eds.). 1984. An Introduction to the Aquatic Insects of North America. Kendall/Hunt Publishing Company, Dubuque, IA, USA.

Muller, K. and V. A. Benignus. 1992. Increasing scientific power with statistical power. Neurotoxicology and Teratology 14:211219.

Murkin, H. R., P. G. Abbott, and J. A. Kadlec. 1983. A comparison of activity traps and sweep nets for sampling nektonic invertebrates in wetlands. Freshwater Invertebrate Biology 2:99-106.

Murkin, H. R. and D. A. Wrubleski. 1988. Aquatic invertebrates of freshwater wetlands: function and ecology. p. 239-249. In D. D. Hook, W. H. McKee, Jr., H. K. Smith, J. Gregory, V. G. Burrell, Jr., M. R. Devoe, R. E. Sojka, S. Gilbert, R. Banks, L. H. Stolzy, C. Brooks, T. D. Matthews, and T. H. Shear (eds.) The Ecology and Management of Wetlands. Volume 1: Ecology of Wetlands. Croom Helm, London, England.

Pennak, R. W. 1989. Freshwater Invertebrates of the United States: Protozoa to Mollusca. John Wiley and Sons, New York, NY, USA.

Perret, N. G. 1962. The spring and summer foods of the common mallard (Anas p. platyrhynchos L.) In south central Manitoba. M.S. Thesis. University of British Columbia, Vancouver, BC, Canada.

Resh, V. H. and J. K. Jackson. 1993. Rapid assessment approaches to biomonitoring using benthic macroinvertebrates. p. 195-233. In D. M. Rosenberg and V. H. Resh (eds.) Freshwater Biomonitoring and Benthic Macroinvertebrates. Chapman and Hall, New York, NY, USA.

Ringelman, J. K. and L. D. Flake. 1980. Diurnal visibility and activity of blue-winged teal and mallard broods. Journal of Wildlife Management 44:822-829.

Ross, L. C. and H. R. Murkin. 1989. Invertebrates. p. 35-38. In E. J. Murkin and H. R. Murkin (eds.) Marsh Ecology Research Program: Long-term Monitoring Procedures Manual. Delta Waterfowl and Wetlands Research Station, Portage la Prairie, MB, Canada.

Sjöberg, K. and K. Danell. 1982. Feeding activity of ducks in relation to diel emergence of chironomids. Canadian Journal of Zoology 60:1383-1387.

Stewart, R. E. and H. A. Kantrud. 1971. Classification of natural ponds and lakes in the glaciated prairie region. U.S. Fish and Wildlife Service, Washington, DC, USA. Resource Publication 92.

Sugden, L. G. 1973. Feeding ecology of pintail, gadwall, American widgeon, and lesser scaup ducklings. Canadian Wildlife Service Report Series 24. Ottawa, ON, Canada.

Swanson, G. A. 1977. Diel food selection by Anatinae on a wastestabilization system. Journal of Wildlife Management 41:226-231.

Swanson, G. A. 1978. Funnel trap for collecting littoral macroinvertebrates. Progressive Fish-Culturist 40:73.

Swanson, G. A. and A. B. Sargeant. 1972. Observation of nighttime feeding behavior of ducks. Journal of Wildlife Management 36: 959-961.

Turner, A. M. and J. C. Trexler. 1997. Sampling aquatic invertebrates from marshes: evaluating the options. Journal of the North American Benthological Society 16:694-709.

Whitman, W.R. 1974. The response of macro-invertebrates to experimental marsh management. Ph.D. Thesis. University of Maine, Orono, ME, USA.

Manuscript received 18 May 1999; revision received 14 September 1999; accepted 15 November 1999. 